Motivation and coping with the stress of assessment: Gender differences in outcomes for university students.

3

$4 \quad$ Arielle Bonneville-Roussy ${ }^{1,2}$, Paul Evans ${ }^{3}$, Jérémie Verner-Filion ${ }^{2}$, Robert J. Vallerand ${ }^{2,4} \&$ 5

11 Acceptance date: $24^{\text {th }}$ August, 2016

12 Thérèse Bouffard ${ }^{2}$

${ }^{1}$ Roehampton University

${ }^{2}$ Université du Québec à Montréal

${ }^{3}$ University of New South Wales

${ }^{4}$ Australian Catholic University

2

4

5

6




\begin{abstract}
The main objectives of the present research were to test a conceptual model linking motivational processes involved in coping with the stress of university assessment, and to examine gender differences in these processes. Self-determined motivation was hypothesized to predict coping strategies and the response to assessment-related stress, and coping was hypothesized to play a considerable role in short- and long-term outcomes of assessment. We examined this model using multiple group path analysis in Mplus. In Study $1(\mathrm{~N}=265)$, music students' use of engagement-coping strategies led to stronger musical career intentions, while disengagement-coping strategies led to weaker intentions. In Study $2(\mathrm{~N}=340)$, students' increased use of engagement coping, and decreased use of disengagement coping strategies led to higher grades, higher positive affect and lower negative affect. In both studies, engagement and disengagement-coping were predicted by autonomous and controlled motivation, respectively. Motivation also indirectly predicted academic outcomes through stress appraisal and coping. While women experienced higher levels of stress, men were more negatively affected by the use of disengagement-oriented coping. Gender differences were also found on the links between engagement-oriented coping and outcomes. These results fill an important gap in the literature regarding gender differences in the outcomes coping in education, as well as contributing to a better understanding of the processes linking motivation, coping and academic outcomes.
\end{abstract}

Keywords: Self-Determination Theory; Stress; Coping; Vocational Intentions; Achievement; Affect, Gender Differences 


\section{Motivation and coping with the stress of assessment: Gender differences in outcomes for university students}

\section{Introduction}

Men and women tend to react differently to stress, women being more likely to perceive events as stressful. Yet, in many educational domains, women tend to outperform men, and to show greater intentions to persist at university, than men (Smith \& Naylor, 2001; Voyer \& Voyer, 2014). What, then, can explain these differences? At university, markers of performance derived from high-stakes assessment are often important determinants of short-term and long-term cognitive and affective experiences of students. When faced with stressful assessment situations, students use strategies with varying levels of effectiveness to attempt to cope with them. Some strategies lead students to study and work toward their goals effectively, deal with the stress of assessment, and achieve positive outcomes, while others lead students to more ineffective study strategies, and maladaptive behaviors such as procrastination and avoidance. The predictors of coping have been the subject of a vast research literature. Research has demonstrated that coping effectively is important for performance and persistence, and that motivation is strongly connected to the kinds of coping strategies people use in evaluation-salient circumstances. Yet there is little conceptual understanding of how motivation, coping, and assessment outcomes are connected.

A large body of evidence has suggested that men and women differ in the way the engage and cope with stressors (Tamres, Janicki, \& Helgeson, 2002), including at school. Two recent meta-analyses of more than 400 studies including students from primary school through to university have indicated that women now outperform men in all areas of education, including mathematics (Richardson, Abraham, \& Bond, 2012; Voyer \& Voyer, 2014). Furthermore, Smith 
1 and Naylor (2001) have found with a sample of more than 400,000 university students, that

2 female students are both more likely to display long term persistence in their chosen academic

3 area than male students, and that persistence for females was significantly less influenced by

4 their grades. Gender differences may also exist in the degree to which males and females benefit

5 from different coping strategies at university (Tamres et al., 2002), but this line of inquiry has not

6 been substantially pursued. In sum, to some extend, female and male students seem to experience

7 short-term and long-term university outcomes differently; these differences may lie in their ways

8 of coping with university-related stress.

9 In the present research, we aimed to more deeply understand motivation, coping with the

10 stress of university assessment experiences, and the impact of coping on short-term performance

11 and affective outcomes, as well as longer-term behavioral intentions to pursue a career in one's

12 chosen area of study. We also aimed to investigate gender differences in light of the evidence that

13 these may be critical in understanding the relationships between these factors.

\section{1.1. An Integrative Model of Motivation and Coping in Academic Settings}

15 This research is grounded in the self-determination theory (SDT; Deci \& Ryan, 1985;

16 Ryan \& Deci, 2000a) and coping perspectives (Lazarus \& Folkman, 1984). Ntoumanis et al.'s

17 (2009) integrative conceptual framework of motivation and coping is especially helpful in

18 understanding how motivation regulations, stress and coping can explain behavioral and

19 psychological outcomes in healthcare settings. Evidence suggests that Ntoumanis et al.'s model

20 is generalizable to educational outcomes and may be an effective way to understand motivation

21 and coping in relation to university assessment. As such, we propose a modified version of

22 Ntoumanis et al.'s model, adapted to educational settings. This adapted model has three main

23 components. First, motivation regulation (autonomous versus controlled motivation) is 
1 hypothesized to have an impact on stress appraisals in evaluative contexts. Second, motivation

2 regulation and stress appraisals in turn lead students to use different coping strategies to face the

3 stress of assessments. Third, the types of coping strategies used are expected to play an important

4 role in the affective, cognitive, and academic experiences of students facing assessment and

5 examinations. Research supporting the relationships in this model is presented in the following

6 sections.

7 1.2. Motivation, Stress, and Coping

8 Coping refers to the actions and thoughts people use to face a situation that is perceived

9 as threatening or stressful (Folkman \& Lazarus, 1985; Folkman, 1984; Lazarus \& Folkman,

10 1991). Coping is one of the more proximal processes that predicts psychological and behavioral

11 responses to stress (Ntoumanis et al., 2009). Hundreds of coping strategies can be identified that

12 can be categorized in a limited number of higher-order categories (Skinner, Edge, Altman, \&

13 Sherwood, 2003). Carver and Connor-Smith (2010) and Connor-Smith et al. (2000; 2007) have

14 further emphasized that the distinction between engagement and disengagement coping strategies

15 might be the most important. Engagement-oriented coping responds to stressful events by using

16 strategies such as planning and positive reinterpretation, while disengagement-oriented coping

17 includes strategies such as disengaging, denial, and blame (Carver, Scheier, \& Weintraub, 1989).

18 Research has agreed that the effectiveness of the various coping strategies is context-specific

19 (Folkman \& Moskowitz, 2004). No individual coping strategy is effective in all situations-the

20 effectiveness of a specific coping strategy depends on its suitability to the stressor (Lazarus \&

21 Folkman, 1984).

22 Coping processes are also thought to be influenced by individuals' motivational

23 orientations in a given situation (Lazarus \& Folkman, 1991; Ntoumanis et al., 2009). SDT 
1 accounts for the different types of motivational orientations that may impact coping processes.

2 The potential of SDT in this context lies in its strong explanatory power in terms of engagement,

3 persistence, and success in a given activity, as well as the psychological consequences of

4 engaging in this activity. SDT proposes that behavioral regulation ranges on a continuum from

5 controlled (e.g., external, introjected) regulation to more autonomous (e.g., identified, integrated,

6 intrinsic) regulation (Ryan \& Deci, 2000b). At the controlled end, behavior is not undertaken for

7 its own sake, but is considered as the means to an external or internal end (e.g. to get a reward, to

8 avoid a punishment, or to relieve internal feelings of guilt). At the autonomous end, behavior is

9 undertaken for its own sake (e.g., for the inner enjoyment, excitement, and interest that is

10 inherent to the learning activity).

11 Motivation influences coping strategies by regulating the appraisal or experience of stress

12 (Ntoumanis et al., 2009). In turn, motivation and stress appraisals lead to distinct coping

13 responses. Students with autonomous motivation are more likely to use more engagement coping

14 strategies, such as planning (Amiot, Gaudreau, \& Blanchard, 2004; Thompson \& Gaudreau,

15 2008), because their behavior is perceived to be initiated and caused by the self, and they thereby

16 feel capable of influencing the outcomes. Students with controlled motivation are more likely to

17 use disengagement coping strategies, such as using distraction, to avoid thinking about an

18 important examination (Amiot et al., 2004; Schellenberg \& Bailis, 2016), because the outcomes

19 of their behavior are perceived to be determined by external influences.

\section{1.3. Motivation, Stress, and Coping at University}

21 The aforementioned research demonstrates that motivation predicts stress and coping.

22 There is mixed evidence for these relationships in relation to short- and long-term outcomes of

23 assessment, or to academic adjustment more broadly defined, and no research to date has 
1 integrated all of these factors in a single empirical model. This section presents evidence

2 supporting the components of our model with three long- and short- term academic outcomes:

3 vocational intentions, achievement, and affect. Examining students' intentions is essential

4 because students are required to make academic choices according to their future vocational

5 intentions early on. Past research has shown that future intentions of students are a key

6 educational outcome that is related to other academic consequences, such as achievement and

7 drop-out (Bong, 2001; Otis, Grouzet, \& Pelletier, 2005; Vallerand, Fortier, \& Guay, 1997). In

8 addition, long-term academic and career goals in adolescence are predictive of career attainment

9 in mid-adulthood (Schoon, 2001), and have been related to domain-specific achievement

10 (Schoon, 2001; Smith \& Naylor, 2001; Titus, 2004). Positive and negative affects have also been

11 shown to be an integral part of academic adjustment (Chemers, Hu, \& Garcia, 2001; Gillet,

12 Vallerand, Lafrenière, \& Bureau, 2012; Zuckerman, Kieffer, \& Knee, 1998).

13 Several studies have found that engagement and disengagement coping were predicted by

14 intrinsic and extrinsic motivation, respectively (Amiot et al., 2004; Moneta \& Spada, 2009).

15 Motivation has been linked directly with academic outcomes, such as achievement, persistence,

16 and positive affect (Ryan \& Deci, 2000a; Taylor et al., 2014; Vallerand et al., 1997). Two

17 experiments, for example, have demonstrated the impact of autonomous versus controlled

18 motivation on assessment outcomes. In the first (Amabile, 1979), college art students painted

19 less creative, and less technically proficient pictures when they were told they would be

20 evaluated. In the second (Grolnick \& Ryan, 1987), elementary school pupils showed less depth

21 of processing and less recall if they were told that the related tests were measures of their ability

22 ('controlling' condition), and better conceptual learning and higher enjoyment if they were told

23 the test was not a measure of their ability and that they could read the text however they wanted 
1 ('autonomous' condition). Assessments in general are known to be perceived as controlled

2 regulation and thereby lead to anxiety, and ill-being (Ryan \& Weinstein, 2009) through their

3 thwarting of basic psychological needs. Autonomous motivation has been linked with the

4 experience of positive affect and controlled motivations to negative affect in university

5 assessment settings (Gillet et al., 2012). A recent systematic review indicated that autonomous

6 goal motivation is positively linked to self-regulatory strategies such as effort expenditure and

7 action planning (Gaudreau, Carraro, \& Miranda, 2012). Self-determined motivation has

8 repeatedly been linked with academic persistence and future vocational intentions (Lavigne,

9 Vallerand, \& Miquelon, 2007; Vallerand et al., 1997). In sum, the accumulated evidence that

10 autonomous and controlled regulations impact the short-and long-term outcomes of assessment

11 is strong (Ryan \& Weinstein, 2009).

12 Few studies have examined the potential stress and copings mediators of the links

13 between self-determined motivation and academic outcomes. Research has shown that high

14 school students who experienced more autonomous motivation were more likely to have the

15 intention to stay in school, that led them to persist in school at a higher rate (Vallerand et al.,

16 1997). In addition, higher levels of autonomous motivation and higher GPA at the end of a

17 semester have been linked with higher intentions to persist in school (Alivernini \& Lucidi, 2011).

18 Controlled motivation has been examined through stress appraisal and fear in relation to

19 assessment. When teachers elicited controlled motivation by reminding students about the

20 consequences of failure, students performed worse in examinations (Putwain \& Remedios,

21 2014). Von der Embse, Schultz, and Draughn (2015) compared the consequences of

22 communicating controlled behavior through fear (reminding students of the consequences of an

23 upcoming exam) with more autonomous behavior (offers to help with preparation). Students who 
1 were exposed to controlled behaviors performed worse than students exposed to efficacy appeals,

2 and stress appraisals did not mediate this relationship. This suggests that another mediating

3 factor such as coping might explain the relationships between controlled motivation and

4 achievement.

5 Coping with university assessments requires considerable engagement with complex

6 skills that need to be demonstrated in order to attain the desired outcomes. In achievement-

7 related domains, engagement coping has been linked to deep and strategic approaches to

8 preparation, while disengagement coping was linked to a more surface approach (Moneta, Spada,

$9 \&$ Rost, 2007). Correlational studies have shown that engagement-oriented coping strategies are

10 linked to positive affect (Ntoumanis, Biddle, \& Haddock, 1999; Rovira, Fernandez-Castro, \&

11 Edo, 2005) and psychological adjustment (Amiot, Blanchard, \& Gaudreau, 2008; Aspinwall \&

12 Taylor, 1992; Gaudreau \& Antl, 2008; Verner-Filion et al., 2014). Engagement-oriented coping

13 has also been associated with objective measures of achievement, such as higher GPA, as well as

14 subjective measures, such as higher levels of performance satisfaction (Kaiseler, Polman, \&

15 Nicholls, 2009; Nicholls, Polman, \& Levy, 2012; Schellenberg \& Bailis, 2016; Zeidner,

16 1995). In the sports domain, van Yperen (2009) has found that engagement-oriented coping, past

17 performances, and firm intentions to pursue a career in a premier league were important

18 correlates of objective career success. More recently, engagement-oriented coping, but not

19 disengagement-oriented coping, was linked to higher achievement after one university semester

20 (Schellenberg \& Bailis, 2016). Conversely, disengagement-oriented coping was related to

21 negative outcomes such as increased burnout and lower levels of subjective well-being

22 (Schellenberg, Gaudreau, \& Crocker, 2013; Verner-Filion et al., 2014). In sum, research 
1 performed in educational and performance contexts mostly has agreed that engagement-oriented

2 coping is associated with better academic and psychological outcomes.

\section{1.4. Gender Differences in Motivation, Stress and Coping}

4 Previous research offers a reasonably reliable portrait of gender differences in the use of

5 coping. In a meta-analysis of the effects of gender in stress and coping with various stressful

6 encounters, Tamres, Janicky, \& Helgeson (2002) found that women perceived events as more

$7 \quad$ stressful and tended to use more coping strategies. But despite these gender differences in coping

8 behaviors between males and females, studies in educational domains have consistently

9 overlooked gender as a moderating variable of the outcomes of coping.

Mean-level gender differences have been found in motivation and coping. Most of the

11 research in gender differences in coping with assessment has been performed in the sports

12 domain, through competition. Women, as compared with men, generally perceive competitions

13 as more stressful and feel that they have less control over their stress (Hammermeister \& Burton,

14 2004; Kaiseler, Polman, \& Nicholls, 2012, 2013). In line with the results of the meta-analysis on

15 gender differences in stress and coping (Tamres et al., 2002), women in achievement situations

16 tend to report more use of coping strategies as a whole (see also Anshel, Sutarso, \& Jubenville,

17 2009; Crocker \& Graham, 1995; Kaiseler et al., 2012, 2013; Knee \& Zuckerman, 1998; Ptacek,

18 Smith, \& Dodge, 1994; Rogowska \& Kusnierz, 2012; Saklofske, Austin, Mastoras, Beaton, \&

19 Osborne, 2012). Comparatively fewer mean-level gender differences have been found in self-

20 determined motivation measures. When such differences were revealed, females tended to score

21 slightly higher on autonomous motivation and males slightly higher on controlled motivation

22 (Ratelle, Guay, Vallerand, Larose, \& Senécal, 2007; Vallerand et al., 1997; Vallerand \& Senécal, 23 1992). 
To our knowledge, no gender differences in the relationships between motivation and measures of stress and coping have been reported in past research. Two studies have investigated

3 gender differences in the coping processes: Anshel et al. (2009) have found that both male and

4 female athletes were likely to use engagement-oriented coping, and unlikely to use

5 disengagement-oriented coping when facing social and performance stressors; Matud (2004)

6 found that in both women and men, disengagement-oriented coping led to less adaptive

7 psychological outcomes. Tamres et al.'s (2002) meta-analysis hinted that men gained more

8 psychological benefits from the use of engagement-oriented coping strategies, but the evidence

9 for this is limited.

\section{1.5. The Present Research}

11 Using two studies conducted in educational settings, this research has three

12 methodological and substantive objectives. First, we aimed at testing a proposed causal model of

13 the structural relationships between motivation, stress, coping, and short-term and long-term

14 academic outcomes (affect, achievement, and career intentions) in higher education. The second

15 objective of the research was to assess gender equivalence of the coping models, particularly in

16 relation to the outcomes of the coping process. Finally, we assessed the generalizability of the

17 findings by examining motivation-coping-outcomes models across two independent samples.

18 Both studies used the same research design: a prospective study spanning one academic

19 term, where motivation was measured at the beginning of the term, coping was measured in the

20 middle, and outcomes at the end (for theoretical and empirical evidence supporting this

21 sequence, see Amiot, Gaudreau, \& Blanchard, 2004; Knee \& Zuckerman, 1998; Ntoumanis,

22 Biddle, \& Haddock, 1999; Ntoumanis et al., 2009; Skinner, Pitzer, \& Steele, 2013; Thompson \&

23 Gaudreau, 2008). Study 1 examined these processes in a sample of music performance students 
1 facing public performances. Public performances in university settings are the favored way of

2 assessing music students, and a jury evaluates these live performances. This specialized and

3 homogenous domain allowed us to examine the impacts of motivation, stress appraisal, and

4 coping with the stress of public assessments on the long-term outcome of career intentions- the

5 extent to which college music students wanted to pursue a career in music performance. Study 2

6 generalized the findings of Study 1 with a sample of university students from various programs,

7 where coping predicted midterm examination performance, as well as positive and negative

8 affect. These students were recruited from programs with differing gender profiles, such as

9 psychology (with a majority of women), mathematics and engineering (with a majority of men),

10 and accounting (with approximately equal representation of men and women). Both studies

11 examined gender differences in the means, variances and regression paths of the proposed model.

12 Based on the research reviewed above, we made the following hypotheses. Hypotheses

13 regarding the structural relations between the variables. We hypothesized that autonomous

14 motivation would relate positively to engagement-oriented coping and negatively to stress

15 appraisal, while controlled motivation would relate positively to stress appraisal and

16 disengagement coping. Furthermore, higher stress during the examination would negatively

17 predict engagement coping and positively predict disengagement coping. We also hypothesized

18 that engagement coping would positively predict intentions, achievement and positive affect, and

19 that disengagement coping would negatively predict intentions, achievement, and positively

20 predict negative affect. Hypotheses regarding gender differences in the motivation-to-coping

21 processes. Since available evidence has overlooked gender differences in the motivation-to-

22 coping processes, past research has seemed to assume that these links were gender-invariant

23 (Amiot et al., 2004; Gaudreau et al., 2012; Ryan \& Connell, 1989; Skinner, Pitzer, \& Steele, 
1 2013). We therefore hypothesized that the links between motivation, stress and coping would be

2 invariant. Mean-level gender differences were found in past research in levels of autonomous

3 motivation and stress, females scoring higher on both (Tamres et al., 2002; Vallerand et al.,

4 1997). We thus expected to find gender differences in autonomous motivation and stress.

5 Hypotheses regarding gender differences in the coping-to-outcomes processes. Finally, since

6 gender differences have been found regarding the ways of coping and their relations to outcomes,

7 we also expect that the relations of coping to intentions, affect and achievement would differ

8 between women and men. However, since this area of research has not been investigated, we do

9 not have specific hypotheses regarding the directionality of these differences.

\section{Study 1}

11 Study 1 aimed to test a model linking motivation, coping, and career intentions of music

12 performance students, and to examine whether there were gender differences in the relationship

13 between coping and career intentions, in line with the aforementioned hypotheses. Studies have

14 noted strong links between academic motivation and educational as well as vocational intentions

15 (Lavigne et al., 2007; Lazarides \& Watt, 2015; Wang, 2012), and that intentions are an important

16 antecedent of future behavior (Ajzen, 2001), including career success (van Yperen, 2009).

17 Research has demonstrated that higher domain-specific motivation has a positive impact on

18 students' vocational interests and choices (see Low, Yoon, Roberts, \& Rounds, 2005). Finally, it

19 is believed that maladaptive coping strategies, and increased stress, impede students' future

20 intentions to stay on in a given career or educational path (Eicher, Staerklé, \& Clémence, 2014).

21 Since musical performances and assessments are inherently stressful (Steptoe, 1989), motivation,

22 stress, and coping strategies may play a particular role in career intentions in this population. 


\subsection{Method}

\subsubsection{Analytical Approach.}

Data were analyzed using structural equation modeling and measurement equivalence. Goodness-of-fit of the measurement and structural models was evaluated according to the recommendations of Marsh et al. (2009): models were deemed to have acceptable fit with a comparative fit index (CFI) equal to or higher than .90 (and an excellent fit equal to or greater than .95) and a root mean square error of approximation (RMSEA) less than .08 (or less than .05 for an excellent fit), with the lower-bound confidence interval closest to zero (0) and the higherbound confidence interval less than .10 . The $\chi^{2}$ values are also presented, a non-significant value indicating an excellent fit to the data. However, recent research has argued that $\chi^{2}$ values are highly sensitive to sample size, and that the $\chi^{2}$ values are almost always significant in moderately complex confirmatory factor analyses (Marsh, Hau, \& Wen, 2004).

The models of the relations between motivation, stress, coping and outcomes, moderated by gender, were examined through structural equivalence (Byrne, 2012). Equivalence of the structural models was assessed in four models. Model 1: The models were tested using one single group to validate the structural relationship between the variables (Byrne \& van de Vijver, 2010; Byrne, 1994, 2012). Model modification indices and error variances were also examined at this stage. Model 2: A second model was tested within a multiple-group framework, with all regression paths, means and variances constrained to be equal, thus testing for equivalence between genders (Byrne, 2012; Marsh, Nagengast, \& Morin, 2013). Model 3: Only the regression weights on the paths directly related to the outcomes were freed to vary between males and females, to examine the hypothesis that the direct links between the predictors and outcomes differ between males and females. Model 4: Gender-equivalence in the estimated 
1 means and variances was tested by freeing the means and variances that contributed the most to

2 the model, according to the model modification indices, theory, and past research. To compare

3 the adequacy of a more restrictive model in measurement invariance, we used several measures

4 according to Chen (2007). A non-significant chi-square change $\left(\Delta \chi^{2}\right)$ indicates that the more

5 constrained model fits the data as well as a less constrained model, and therefore that the models

6 are equivalent. If the chi-square change statistics were significant and indicative of an ill-fitted

7 model, we then examined changes in the other model fit indices between a less constrained and a

8 more constrained model. Chen indicated that a change in CFI and TLI equal to or less than .010

9 complemented by a change of less than .015 in RMSEA would indicate a good model fit. In sum,

10 a better model would be indicated by a stable or significant decrease in chi-square, and a stable

11 or increase in CFI, TLI and RMSEA (Chen, 2007).

12 Finally, we used SEM to assess the equivalence of our measurement instruments between

13 men and women in sections 2.1.3, and 3.1.3. Measurement invariance relates to equivalence

14 across gender at the structural (number and composition of factors), metric (factor loadings) and

15 scalar levels (item intercepts; Byrne \& van de Vijver, 2010). Measurement invariance has been

16 demonstrated in self-determined motivation and coping, so it appears unlikely that gender

17 differences in measurement are strong (Gaudreau \& Blondin, 2002; Grouzet, Otis, \& Pelletier,

18 2006). Measurement invariance was assed with the aforementioned thresholds (Chen, 2007).

19 When invariance testing was successful, mean-centered factor scores of the variables were saved

20 and those scores were used in the main analyses. All analyses were carried out using Mplus

21 version 7.3 (Muthén \& Muthén, 2010).

22 2.1.2. Participants 
Participants were 296 music students who were part of a larger longitudinal study aimed

2 at assessing the correlates of music performance and persistence. These students were recruited

3 from various music classes in two colleges that offered specialized training in music. The study

4 covered half a term of their college degree. Out of these students, two cases had missing values

5 on all of the variables included in the present study, and 14 students did not specify their gender.

6 These students were removed from the dataset. Out of the 280 students with valid entries, a

7 preliminary analysis of outliers revealed 15 outlier cases (Standardized Mahalanobis Distance <

$8 \pm 2.5$ ). These outliers had particularly low scores on autonomous motivation as compared with

9 their group means. The remaining analyses were performed with a sample size of 265, of which

10151 were males and 114 were females. The students were aged $16-30$ years $(M=18.06$,

$11 S D=1.81)$

\subsubsection{Measures.}

Autonomous and controlled motivation (T-1). We used a short version of the Academic

14 Motivation Scale, college version (16 items; Grouzet et al., 2006; Vallerand et al., 1992, 1993) to

15 measure students' level of motivation towards their music education. Participants rated items on

16 a 7-point scale ranging from 1 (strongly disagree) to 7 (strongly agree). Based on the motivation

17 regulations inherent to SDT (Deci \& Ryan, 1985; Ryan \& Deci, 2000b), we measured four types

18 of motivation: external regulation (e.g., "in order to have a better salary later on"); introjected

19 regulation (e.g., "because I want to prove myself that I can succeed at school"); identified

20 regulation (e.g., "because this will help me make a better career choice"); and intrinsic

21 motivation (e.g., "For the pleasure I experience in broadening my knowledge about interesting

22 subjects"). A second-order CFA supported the validity of the four motivation subscales as well as

23 the division between autonomous motivation (intrinsic and identified regulations, $\alpha=.66$ ) and 
1 controlled motivation (introjected and external regulations, $\alpha=.80$ ), $\chi^{2}(98)=148.82, p<.001$;

$2 \mathrm{CFI}=.96 ; \mathrm{TLI}=.95 ; \mathrm{RMSEA}=.04(.03, .06)$. Past research has also demonstrated the

3 longitudinal and gender equivalence of the measure (Grouzet et al., 2006). In the present study,

4 configural, metric and scalar measurement equivalence between genders was performed with the

5 four motivation regulations, as Mplus does not allow for measurement equivalence testing of

6 second-order factor analyses. The motivation scale was equivalent across gender at the scalar

7 level, all $\Delta \chi^{2}>.05$, and the configural model fit the data adequately, $\chi^{2}(196)=259.30, p<.002$;

$8 \quad \mathrm{CFI}=.95 ; \mathrm{TLI}=.94 ; \mathrm{RMSEA}=.05(.03, .06)$.

Stress Appraisal (T-2). Students were asked to evaluate on a 5-point scale ranging from 1

10 (very low) to 5 (very high) their perceived level of stress during general public music

11 performance situations $(M=3.49, S D=.97)$. This measure was a used as a proxy for stress under

12 examination, as music performance examinations are usually public performances.

13 Coping (T-2). A 14-item version of the Brief Cope (Carver, 1997) was used to measure

14 engagement and disengagement coping strategies. Students rated on a 5-point scale ranging from

151 (not at all) to 5 (very strongly) how each item matched how they were generally managing

16 stress in public music performance situations. CFA results were adequate for the engagement-

17 disengagement structure, $\chi^{2}(140)=268.60, p<.001 ; \mathrm{CFI}=.92 ; \mathrm{TLI}=.90 ; \mathrm{RMSEA}=.06$

18 (.05, .07). The six engagement items (e.g., "I've been trying to see the situation in a different

19 light, to make it seem more positive") were taken from the active coping, planning, and positive

20 reinterpretation subscales of the Brief Cope $(\alpha=.78)$. The eight disengagement items (e.g., "I've

21 been turning other activities to take my mind off things") were obtained from the subscales

22 measuring denial, behavioral and mental disengagement, and self-blame $(\alpha=.68)$. 
Configural invariance between gender fit the data adequately, $\chi^{2}(277)=389.18, p<.001$;

$2 \mathrm{CFI}=.92 ; \mathrm{TLI}=.90 ; \mathrm{RMSEA}=.06(.05, .07)$. Metric and scalar invariance were met, with the

3 chi-square difference test between the metric and the scalar levels being above the level of

4 significance. In sum, measurement invariance was achieved with the Brief Cope by allowing one

5 item loading to be freely estimated ${ }^{1}$.

$6 \quad$ Career intentions (T-2). This scale designed for the purpose of the present study assessed

7 in 7 items on a scale ranging from 1 (strongly disagree) to 7 (very strongly agree), the extent to

8 which music students wanted to pursue a career in music performance after their studies. CFA

9 confirmed the presence of two dimensions, with an excellent model fit, $\chi^{2}(32)=44.83 p=.07$;

$10 \mathrm{CFI}=.96 ; \mathrm{TLI}=.95 ; \mathrm{RMSEA}=.06(.00, .10)$. The first dimension encompassed music

11 performance intentions (5 items, e.g., "I intend to play in a band/orchestra," $\alpha=.68$ ), and the

12 second dimension covered music teaching (2 items, e.g., "I intend to become a

13 primary/secondary school music teacher," $\alpha=.71$ ). Because we were interested in evaluating the

14 musical intention of the music students, only the music performance future intention subscale

15 was retained for further analysis. The measure of musical intentions was gender-equivalent at the

16 scalar level, all $\Delta \chi^{2} p>.19$.

\section{2.2. Procedure}

The participants completed surveys on two occasions across one academic term. On the

19 first occasion, participants completed a consent form and a survey containing socio-demographic

20 information and the autonomous and controlled motivation measures. On the second occasion,

21 immediately following mid-term, they completed the stress appraisal measure, the engagement

22 and disengagement coping measures, and the items relating to career intentions. The second

23 occasion was two months after the first. 


\subsection{Results and Brief Discussion}

Table 1 shows first-order correlations, means and standard deviation of the variables

3 included in this study. The analyses were conducted using the four steps described in Section

4 2.1.1. Model fit indices for the four models are presented in the first section of Table 2. Model 1:

5 We assessed the whole structural model in a single-group analysis framework. This model did

6 not fit the data well. Model modification indices indicated that adding a direct link between

7 autonomous motivation and career intentions would improve the model. Since this link was well-

8 supported in previous research (e.g., Vansteenkiste, Simons, Lens, Sheldon, \& Deci, 2004) it was

9 then included in the model. This model fit the data adequately (Model 1b, in the first section of

10 Table 2). In sum, the single-group analysis confirmed our theoretical model, with the addition of

11 a direct link between autonomous motivation and career intentions.

12 Model 2: Taking Model $1 \mathrm{~b}$ as the baseline, we evaluated the structural model in a

13 multiple-group framework, whereby the regression paths, means and variances are constrained to

14 be equal between males and females. This model did not fit the data well, meaning that the paths

15 between females and males were significantly different. Model 3: We examined model fit where

16 gender differences were modeled by freeing the regression weights between coping and career

17 intentions, allowing them to differ between men and women. In this model, means and variances

18 were constrained to be equal between men and women, except for the estimated mean-levels of

19 stress, for which strong gender differences have been found in past research (Tamres et al.,

20 2002). This model fit the data better but still did not meet the threshold of model adequacy.

21 Model 4: Finally, results of the modification indices indicated that freeing the intercepts

22 of career intentions and disengagement coping would improve the model further. This model was

23 an excellent fit to the data, and the standardized solution is presented in Figure 1. Unstandardized 
1 beta coefficients, their standard errors, and standardized beta coefficients are presented in Table

2 3. The following paths were equivalent across gender. Non-significant links between stress

3 appraisal and the two forms of motivation were found. Engagement coping was predicted by

4 autonomous motivation. Disengagement coping was predicted by controlled motivation and by

5 stress appraisal. Gender differences were found on the link between career intentions and

6 engagement coping. Whereas for males, a positive link was found between the use of

7 engagement-oriented coping strategies and career intention, this link was not significant for

8 females. Career intentions were predicted negatively by disengagement coping for females, but

9 not for males and positively by autonomous motivation, similarly for males and females. Men

10 and women differed in their levels of career intentions, men scoring higher than women (men: $M$

$11=5.21, S E_{\mathrm{M}}=.19$; women: $\left.M=4.12, S E_{\mathrm{M}}=.21\right)$. Men had lower scores on disengagement

12 coping (men: $M=-.31, S E_{\mathrm{M}}=.07$; women: $M=-.23, S E_{\mathrm{M}}=.08$ ). Finally, women scored higher

13 on stress appraisal (men: $M=3.25, S E_{\mathrm{M}}=.09$; women: $M=3.77, S E_{\mathrm{M}}=.10$ ).

14 Moderated mediation results were also found in the model. For men, autonomous

15 motivation indirectly predicted career intentions through engagement-oriented coping, .16 (95\%

16 C.I. $=.01 ; .31), \mathrm{z}=2.04, p=.04$. For women, disengagement coping mediated the link between

17 controlled motivation and career intentions, -.17 (95\% C.I. $=-.33 ;-.01), \mathrm{z}=-2.13, p=.03$.

18 Overall, this model explained $11 \%$ of the variance in career intentions for both men and women.

In sum, Study 1 established relationships between motivation, stress appraisals, coping,

20 and career intentions of music students in the context of music performance examination.

21 Autonomous motivation was particularly relevant not only for the development of effective

22 coping strategies, but also had a direct influence on students' career intentions. Controlled

23 motivation resulted in the use of disengagement coping strategies. The model supported the 
1 relevance of coping strategies for career intentions in very stressful academic environments. As

2 expected, gender differences were found in some means and in the predictive associations

3 between coping and the outcome.

4

\section{Study 2}

The purpose of Study 2 was twofold. First, we wanted to generalize the predictive validity of the motivation-stress-and coping model by measuring the context of university assessment in a range of academic domains. The second aim was to confirm the findings of Study 1 on gender differences in assessment performance as well as positive and negative affect.

\subsection{Method}

\subsubsection{Analytical Approach.}

The analytical approach was identical to Study 1 (see Section 2.1.1.), in which gender invariance was first examined for each of the measures, followed by a procedure to establish structural relations and then test them for differences in these relations.

\subsubsection{Participants.}

The sample of Study 2 comprised 350 students attending one single university in Quebec, Canada. They were enrolled in 13 different classes: 5 classes in engineering, mathematics and computer sciences $($ women $=11 \%), 3$ in business and accounting $($ women $=60 \%)$, and 5 in psychology and health care $($ women $=81 \%$ ). Out of these 350 students, five did not specify their gender and three had missing values on all of the variables included in the core model. Out of the 342 valid entries, two outlier cases were identified that scored much lower in the examination than the other participants. These cases were removed from the dataset and the final sample comprised 340 participants, aged 19 to 57 years $(M=27.50, S D=7.40)$, of which 136 were men and 204 were women. 


\subsubsection{Measures}

Academic Motivation (T-1). The same measure as in Study 1 was used. In the present study, participants rated on a 5 -point scale ranging from $1=$ strongly disagree to $5=$ strongly agree, the extent to which each of the statements corresponded to why they studied in their chosen program at university. A second-order CFA analysis supported the validity of the four motivation subscales ( $=.07(.06, .08)$. The reliability coefficients for this second-order structure were, for autonomous motivation, $\alpha=.77$, and for controlled motivation, $\alpha=.82$.

Tests for measurement equivalence results indicated that the motivation scale was equivalent across gender at the partial scalar level, with all fit indices being within their threshold for invariance, except the chi-square difference that was significant for the difference between metric and scalar $\Delta \chi^{2}(12)=27.87, p=.006^{2}$. Model fit information for the configural model is as follows: $\chi^{2}(186)=358.42, p<.001 ; \mathrm{CFI}=.92 ; \mathrm{TLI}=.90 ; \mathrm{RMSEA}=.08(.07, .09)$.

Stress Appraisal (T-1). Students were asked to evaluate on a 5-point scale ranging from 1 $=$ very low to $5=$ very high, their perceived level of stress during exams $(\mathrm{M}=2.99, \mathrm{SD}=1.05)$. Coping (T-2). Coping was assessed immediately after the mid-term exam. Similar to Study 1, we administered the Brief Cope (Carver, 1997) to measure engagement and disengagement coping strategies, with the same rating scale. However, students were asked to evaluate the coping strategies used in preparation for this specific exam. CFA results confirmed the adequacy of the engagement-disengagement coping factors, with the same items included in each factor as in Study $1, \chi^{2}(162)=328.92, p<.001 ; \mathrm{CFI}=.92 ; \mathrm{TLI}=.91 ; \mathrm{RMSEA}=.06$ $(.05, .07)$. Alpha coefficients were $\alpha=.78$ for engagement-coping, and $\alpha=.73$ for disengagement-coping. Results of configural equivalence showed that the model was an 
1 acceptable fit to the data, $\chi^{2}(324)=550.43, p<.001 ; \mathrm{CFI}=.91 ; \mathrm{TLI}=.90 ; \mathrm{RMSEA}=.07$

$2(.06, .08)$. Metric invariance was confirmed, the changes in model fit information being within

3 the thresholds (Chen, 2007). Scalar equivalence was also met for four out of five model fit

4 indices (except chi-square difference).

Positive and negative affect (T-2). Immediately after the mid-term exam, students were

6 asked to rate their mood state at present, using the Positive and Negative Affect Schedule

7 (PANAS; Watson, Clark, \& Tellegen, 1988; Watson \& Clark, 1999). Participants rated, on a 5-

8 point scale ranging from 1 (not at all) to 5 (extremely), the extent to which each of the 10

9 emotions included in the present study matched to the way they were feeling. Examples of items

10 include "excited" and "proud" for the positive affect subscale $(\alpha=.81)$, and "distressed" and

11 "irritable" for the negative affect subscale $(\alpha=.86)$. A CFA performed on the items confirmed

12 the adequacy of a two-factor structure, $\chi^{2}(31)=74.14, p<.001$; CFI $=.96$; TLI $=.94$; RMSEA

$13=.08(.06, .10)$. Configural and metric invariance were met, with the configural fit indices as

14 follows: $\chi^{2}(62)=122.98, p<.001 ; \mathrm{CFI}=.95 ; \mathrm{TLI}=.92 ; \mathrm{RMSEA}=.09(.07, .12)$. The partial

15 scalar invariance model indicated a good fit, $\Delta \chi^{2}(7)=8.71, p=.27^{3}$.

16 Achievement (T-3). Results of the mid-term exams were collected from the courses

17 tutors. Most of the results were given in percentage. One teacher graded the results in letters

18 (ranging from $\mathrm{A}+$ to $\mathrm{F}$ ), and these results were converted back to percentage using the

19 departmental memo on the grading system. Mid-term exams grades ranged from $23 \%$ to $100 \%$

$20(M=75.80, S D=16.26)$. We centered the students' grades around their course average, so that

21 their scores represent the deviation from their own course's mean.

\section{3.2. Procedure}


This study spanned one academic term. Participants completed the first survey in their

2 respective classes, along with a consent form, at the beginning of the term, and the second survey

3 right after their class-related mid-term exam, one month later. In the consent form, students were

4 asked their permission for the researchers to be provided with midterm examination results.

5 These results were made available two months after the beginning of term. All questionnaires

6 were answered in French.

\section{3.3. Results and Brief Discussion}

The same steps as in Study 1 were followed in the present study. Goodness of fit

9 information for the four models is presented in the second section of Table 2. Correlation results,

10 means and standard deviations are presented in Table 4. Model 1: The first single-group analysis

11 model did not reveal an adequate fit to the data, that could be improved by adding a direct path

12 between stress appraisal and negative affect (Ntoumanis et al., 1999). That is, our overall model

13 was supported, with the addition of a direct path between stress and negative affect (Model $1 \mathrm{~b}$ ).

14 Model 2: On the basis of this single group model, the multiple group, fully gender-equivalent,

15 model did not fit the data well, confirming that the paths were not equivalent between genders.

16 Model 3: The model in which regression weights between coping and the outcome variables

17 (positive and negative affect, and examination results) significantly improved the model but still

18 did not fit the data adequately. Model 4: An examination of the model modification indices

19 revealed that allowing the estimated means/intercepts and variances of autonomous motivation

20 and stress appraisal to be freely estimated between men and women would lead to an excellent

21 model fit. This model was an excellent fit to the data.

The unstandardized and standardized beta coefficients, as well as standard errors are

23 shown in Table 5 and the standardized results are displayed in Figure 2. The regression paths 
1 presented next were gender-equivalent. Autonomous motivation positively predicted engagement

2 coping. Controlled motivation was positively linked with both stress appraisal and

3 disengagement coping. Stress was positively related to disengagement coping.

4 The associations between the predictors and outcomes were mostly gender non-

5 equivalent. Positive emotions were negatively predicted by disengagement-oriented coping, with

6 stronger associations for men than for women. The association between engagement-oriented

7 coping and positive affect was not significant for men, and significantly positively related for

8 women. Negative affect was positively associated with disengagement coping, and this

9 relationship was stronger for men. The associations between negative affect and engagement

10 coping were not significant for men and women. Negative affect was not significantly linked

11 with stress appraisal for men but positively associated for women. Examination results were

12 more strongly predicted by disengagement coping for males than for females, with a very large

13 negative effect of disengagement coping on the grade for males, and medium effects for females.

14 The links between examination results and engagement-oriented coping was not significant.

15 We also found moderated indirect effects between the predictors and outcomes. For male

16 students, the indirect effects between controlled motivation and examination results via stress

17 appraisal and disengagement coping was significant, $-1.37(95 \%$ C.I. $=-2.47 ;-.27), \mathrm{z}=-2.85, p$

$18=.004$, and also via disengagement coping only, $-3.24(95 \%$ C.I. $=-5.39 ;-1.09), \mathrm{z}=-2.66, p$

$19=.008$. The links between controlled motivation and positive affect was mediated by stress

20 appraisal and disengagement coping, $-.03(95 \%$ C.I. $=-.06 ;-.01), \mathrm{z}=-2.33, p=.02$, and also via

21 disengagement coping only, $-.08(95 \%$ C.I. $=-.14 ;-.03), \mathrm{z}=-2.22, p=.03$. The associations

22 between controlled motivation and negative affect were mediated by disengagement coping, .20 
$1 \quad(95 \%$ C.I. $=.08 ; .31), \mathrm{z}=2.64, p=.008$ and a combination of disengagement coping and

2 stress, $.08(95 \%$ C.I. $=.01 ; .15), \mathrm{z}=2.82, p=.005$.

3 For female students, three indirect effects were found. First, autonomous motivation and

4 positive emotions were mediated by engagement-oriented coping $.09(95 \%$ C.I. $=.01 ; .17), \mathrm{z}=$

$52.77, p=.006$. The associations between controlled motivation and positive affect was mediated

6 by stress appraisal and disengagement coping, $-.02(95 \%$ C.I. $=-.04 ;-.001), \mathrm{z}=-2.06, p=.04$,

7 and also via disengagement coping only, $\beta=-.05(95 \%$ C.I. $=-.09 ;-.01), z=-2.32, p=.02$.

8 Indirect effects were found between controlled motivation, stress and negative affect, .11 (95\%

9 C.I. $=.03 ; .19), \mathrm{z}=2.93, p=.003$, controlled motivation, disengagement-oriented coping and

10 negative affect, $.11(95 \%$ C.I. $=.01 ; .20), \mathrm{z}=2.60, p=.009$, and finally controlled motivation, a

11 combination of stress and disengagement-oriented coping, and negative affect, .05 (95\% C.I.

$12=.01 ; .08), \mathrm{z}=2.77, p=.006$

13 In terms of mean-level differences, women had higher estimated scores on autonomous

14 motivation (men: $M=-.14, S E_{\mathrm{M}}=.05$; women: $M=.09, S E_{\mathrm{M}}=.03$ ), and stress appraisal (men:

$15 M=2.56, S E_{\mathrm{M}}=.09$; women: $\left.M=3.29, S E_{\mathrm{M}}=.06\right)$. This model explained $21 \%$ of the variance

16 in positive affect for male students and $29 \%$ for females, $51 \%$ of the variance in negative affect

17 for males, and $34 \%$ for female students, and $58 \%$ of the variance in examination results for men

18 as compared with $8 \%$ for women.

An alternative model to the aforementioned main model was tested according to Gillet,

20 Vallerand, Lafrenière, \& Bureau (2012)'s empirical investigation, whereby the core model

21 leading to coping would remain the same, but positive and negative affect would lead to

22 performance (with the addition of gender non-equivalent regression paths between affect and

23 performance). This alternative model did not fit the data as well as the preceding model, $\chi^{2}(40)$ 
$1=65.38, p=.009 ; \mathrm{CFI}=.94 ; \mathrm{TLI}=.92 ; \mathrm{RMSEA}=.06(.03, .09)$, and the parsimony fit indices

2 favored the main model (Main Model AIC $=5036.77$; Alternative Model AIC $=5048.13$ ).

3 Therefore, the main model (Model 4) was retained.

4 To sum up, three important findings were revealed from Study 2. First, the causal

5 relationships found in Study 1 were replicated in Study 2, with the addition of a link between

6 controlled motivation and stress. Second, the relationships between coping and outcomes were

7 confirmed; disengagement-oriented coping was revealed to be an important predictor of negative

8 outcomes. Finally, assessment of structural equivalence revealed strong gender differences,

9 especially in the relationships between disengagement-oriented coping and outcomes.

10 3.4. Equivalence of the Core Model across Studies

11 To evaluate the structural equivalence of the core model between Study 1 and Study 2 we

12 merged the two datasets with the variables included in both studies (autonomous and controlled

13 motivation, stress appraisal, as well as engagement and disengagement coping; $\mathrm{N}=604$, see

14 Sections 2.1.2 and 3.1.2 for information about participants).

15 We performed a 2x2 (Gender X Study) structural equivalence SEM with the fully

16 equivalent paths found in Study 1 and Study 2. We took the core model of Study 2 linking

17 motivation to stress and coping as the main model to test for structural invariance (see Figure 2)

18 and the core relationships between the variables of the model of Study 1 as the alternative model

19 (see Figure 1). We hypothesized that the regression model would be fully equivalent across

20 studies and gender, as per the results of Studies 1 and 2. We standardized the variables so that the

21 means and variances were comparable between samples, and tested for the equivalence of the

22 regression paths only. 
The fully equivalent model based on Study 2 fit the data very well, $\chi^{2}(28)=30.55, p$

$2=.34 ; \mathrm{CFI}=.99 ; \mathrm{TLI}=.98 ; \mathrm{RMSEA}=.03(.00, .08)$. As an alternative, the model presented in

3 Study 1 was performed by removing the direct link between controlled motivation and stress

4 appraisal. This model provided a less good fit to the data, $\chi^{2}(29)=37.81 \mathrm{p}=.13 ; \mathrm{CFI}=.95 ;$ TLI

$5=.95 ; \mathrm{RMSEA}=.05(.00, .08)$. The parsimony adjusted AIC index favored the model base on

6 Study 2 (Study 2 model AIC = 3789.79; Study 1 model AIC = 7127.64). In sum, measurement

7 equivalence results comparing the two studies on the links between motivation, stress, and

8 coping, confirmed gender invariance of those links, with a better fit to the pooled data obtained

9 with the model presented in Study 2.

\section{General Discussion}

11 The findings from this research inform our understanding of the causal relationships

12 between motivation, stress, coping processes, and the psychological outcomes of coping in the

13 context of university assessment. In line with past research, we have examined our proposed

14 model with three inter-related academic outcomes: affect, achievement and vocational intentions

15 (Bong, 2001; Gillet et al., 2012; Lavigne et al., 2007; Schoon, 2001). We also addressed the need

16 to examine gender differences in the magnitude of the relationships between coping and

17 outcomes, have found large effects, and generalized the findings in two independent samples.

18 Study 1 pursued these objectives in a sample of university music students, while Study 2

19 generalized these findings to other subject areas. The results largely supported the hypothesized

20 model, which drew on our conceptual model adapted from Ntoumanis et al., (2009) and on other

21 previous research. Autonomous motivation predicted engagement coping strategies (Study 1 and

22 Study 2), while controlled motivation predicted stress (Study 2) and disengagement coping

23 strategies (Study 1 and 2). Coping strategies in turn predicted psychological outcomes: career 
1 intentions (Study 1), grades (Study 2), and positive and negative affect (Study 2). We examined

2 gender differences in not only mean levels of coping and outcomes but also the magnitude of

3 relationships between coping and outcomes, and found large effects. Cross-validation results

4 demonstrated the equivalence of the proposed model between studies.

5 4.1. On the Relationships between Motivation, Stress and Coping with Assessment

6 Our research performed with two independent samples confirmed the validity of a

7 predictive model linking motivation, stress appraisal and coping. Autonomous and controlled

8 motivation regulations were found to predict engagement coping and disengagement coping

9 respectively, a link that has been connected similarly in previous research (e.g., Amiot et al.,

10 2004; Doron, Stephan, Boich, Julie, \& Le Scanff, 2009). Autonomous motivation results from a

11 social environment that communicates a sense of competence, relatedness, and autonomy, and is

12 characterized by behavioral regulation that is perceived to emanate from the self. In contrast,

13 controlled motivation communicates a social environment that is more judgmental. Our findings

14 corroborate a large body of evidence that autonomous motivation leads to engagement, while

15 controlled motivation leads to stress and a focus on disengagement and avoidance. In the

16 university context, and in education more broadly, the controlling and pervasive nature of

17 assessments (Deci, Vallerand, Pelletier, \& Ryan, 1991) may lead to broad negative impacts on

18 students' adjustment. In the classical music tradition this is particularly salient. Classical music

19 pedagogy has a long history of cultivating conformity and adherence to strict rules. While other

20 domains of teaching (e.g., school) have changed considerable over the last century or so, the

21 teaching style in studio classical music training is steeped in a master-apprentice model, in which

22 the teacher is the active and prescriptive expert, and the student is passive (Gaunt, 2008;

23 McPherson \& Gabrielsson, 2002). Recent research has concluded that advanced classical music 
1 training might still be rather controlling (Evans, 2015; Syrjala, Saarela, \& Lehtonen, 2005). The

2 musicians investigated in Study 1 might have been affected by this overall culture of control. The

3 students in Study 2 might also have experienced the more thwarting effects of lack of autonomy

4 caused by the controlling context of university assessment.

5 The present research also made the unique contribution that autonomous motivation

6 influences coping directly, and that controlled motivation directly predicts disengagement

7 coping, but also works through stress and disengagement coping to predict academic outcomes.

8 In theoretical terms, these findings show that motivation, coping, and outcomes can be brought

9 together to better explain the outcomes of coping processes. In practical terms, students who

10 attend university because they enjoy learning and are motivated by their own achievements are

11 more likely to use more adaptive, engagement-oriented coping strategies, such as planning their

12 assessment, and use positive cognitive reframing. On the contrary, students who attend university

13 for more controlled reasons, for instance to please others or to have a better salary later on, are

14 more likely to feel stressed and to use avoidance-oriented coping strategies, such as distracting

15 themselves away from the assessment to avoid thinking about it. Our findings highlight that the

16 motivation-stress-coping paths in turn influence academic adjustment as a result of university

17 assessment.

\section{4.2. The Impact of Coping on Assessment Outcomes}

19 Our study confirmed the benefits of the use of engagement-oriented coping and the

20 thwarting effects of disengagement-oriented coping in reaching adaptive outcomes at university.

21 In Study 1, men's vocational intentions were best explained by engagement coping, while

22 disengagement coping more negatively impacted women's vocational intentions. In Study 1,

23 women also tended to appraise music performances as more stressful than men. Past research has 
1 shown both that music performance is extremely stressful (Steptoe, 1989), and that musicians are

2 more likely to drop-out in environments perceived as highly pressuring and stressful

3 (Bonneville-Roussy, Vallerand, \& Bouffard, 2013). In the present research, it is possible that

4 women tended to react to their higher levels of performance-related stress by avoiding stressful

5 situations, that in turn made them want to pursue an inherently stressful career in music less than

6 men. In this sense, women's diminished career intentions may have been an adaptive response to

7 the appraisal of high stress and the consideration that a career characterized by such stress is

8 undesirable. In Study 2, disengagement predicted all outcomes, while engagement coping only

9 predicted positive affect, and only for women. Disengagement-oriented coping involves less

10 flexible and organized strategies that do not deal with the stressful situation directly (Skinner et

11 al., 2003). As such, during assessment periods, students who use disengagement-oriented

12 strategies may spend a significant amount of time away from the stressor, trying to avoid it, that

13 lead them to experience less positive and more negative feelings and poorer objective grades as a

14 result of their examination. This result was especially significant for men.

15 We also expected engagement coping to predict examination results, similar to the way

16 that approach coping predicted results in Schellenberg and Bailis's (2016) study. However,

17 engagement coping played a far smaller role in our results than disengagement coping. It is

18 possible that our modeled gender effects clarified the relationships between the different ways of

19 coping and outcomes. Had Schellenberg and Bailis's model accounted for gender differences in

20 the outcomes of coping, they may have uncovered different results on the impact of

21 disengagement coping. Nevertheless, our finding that disengagement-oriented coping strategies

22 predicted less adaptive outcomes is in line with past research that has found similar results with

23 regards to goal attainment and affect in athletic competitions (Amiot et al., 2004; Gaudreau \& 
1 Blondin, 2002). Practically, our results support the findings that students who generally follow

2 the more adaptive autonomous motivation and engagement-oriented coping path are also more

3 likely to experience more positive affect, better grades, and long-term engagement with their

4 studies.

\section{$5 \quad$ 4.3. Gender Differences in Coping Outcomes}

6 Looking at gender differences in the outcomes of coping was a key objective in this

7 investigation. First, the assessment of multiple group measurement equivalence is an important

8 step to ensure that the questionnaires used are interpreted in similar ways between men and

9 women. Our results revealed that both the Academic Motivation Scale and the Brief COPE were

10 gender-equivalent. This means that both the motivation and coping measures used were

11 understood and rated the same way by men and women in the present research. This result

12 corroborates the findings of past research regarding gender-invariance of coping and motivation

13 measures (Gaudreau, El Ali, \& Marivain, 2005; Grouzet et al., 2006).

14 We hypothesized that the core of the model (structural relations between motivation,

15 stress appraisal, and coping) would be gender-invariant. This assumption was grounded on the

16 fact that no gender difference, was reported in research that has specifically assessed these

17 processes (Amiot et al., 2004; Gaudreau et al., 2012; Ryan \& Connell, 1989; Skinner et al.,

18 2013). We indeed found that all of the motivation-to-coping processes were equivalent amongst

19 our female and male student samples, also across studies, and in line with the results of past

20 research. That is, autonomous motivation predicted engagement-oriented coping, whereas

21 controlled motivation was associated to stress-appraisal and disengagement-oriented coping.

22 We found mean-level differences in the estimated measures of stress appraisal,

23 disengagement coping and career intentions in Study 1 and autonomous motivation and stress 
1 appraisal in Study 2, females scoring higher on most of these measures (except career

2 intentions). The fact that women tend to score higher on stress and coping measures has been

3 well documented in past research (Matud, 2004; Tamres et al., 2002). Females experiencing

4 higher levels of stress may be prone to use more coping strategies, including disengagement

5 coping, to try to face the increased stress. The estimated mean of autonomous motivation was

6 found to be higher for females in Study 2, only, replicating the results of past research (Vallerand

7 et al., 1997). However, the observed means of Table 1 show that, when the other variables were

8 unaccounted for, the mean of autonomous motivation was also slightly higher for females in

9 Study 1. This slight discrepancy between the results of Study 1 and Study 2 highlights the

10 importance of controlling for the influence of all variables in a given model, even when reporting

11 mean differences. The means of all other variables were found to be equivalent across gender.

12 Therefore, finding such strong similarities in the regression weights and most of the means

13 between male and female students in the motivation-to-coping processes suggests that it will be

14 fruitful for educational researchers to explore other mechanisms that might explain the strong

15 gender differences found in the outcomes of coping.

16 We found that disengagement-oriented coping explained most of the gender differences.

17 This result was surprising, since past research has found mixed to no gender differences in the

18 effectiveness of the coping strategies in achievement domains (Lawrence, Ashford, \& Dent,

19 2006; Nicholls, Polman, Levy, Taylor, \& Cobley, 2007; Ptacek et al., 1994). Disengagement

20 coping particularly affected men's performance on examinations: One unit increase in

21 disengagement-oriented coping directly translated into a failure for male students with a loss of

2261 points out of 100 , but for females the loss was only 17 points. This difference is surprising

23 given that the examinations occurred under similar circumstances and that women experienced 
1 more stress in relation to examinations. One hint of explanation can be found in research that

2 suggests that women tend to seek social support much more than men (e.g., Lengua \&

3 Stormshak, 2000; Matud, 2004; Ptacek et al., 1994). Although seeking support has been

4 theoretically associated with engagement coping (e.g. Gaudreau \& Blondin, 2002) and with

5 emotion-oriented coping (that sometimes is associated with disengagement coping; e.g. Nicholls

6 \& Polman, 2007), others have emphasized on its overall adaptive nature in dealing with stressful

7 situations (Skinner et al., 2013). In addition, research has found that, from a young age, female

8 students were more likely to use self-regulation strategies, such as planning and monitoring, than

9 male students (Zimmerman \& Martinez-Pons, 1990). Therefore, women might use social support

10 and self-regulation strategies to buffer the negative effects of stress and disengagement-coping

11 strategies much more than men, for instance by seeking ways to increase their overall study

12 effectiveness. The moderating role of social support and self-regulation to explain the links

13 between disengagement-oriented coping and outcomes are interesting avenues for future

14 research.

15 Engagement-oriented coping strategies were also a source of gender differences, but led to

16 mixed results in the present research. With our specialized sample of musicians, the use of

17 engagement coping strategies, such as planning, predicted future musical career intentions in the

18 sub-sample of men. This result supports the hypothesis that males might benefit the most from

19 the use of engaging strategies. With our general sample of students in various domains, we found

20 little effects of engagement-oriented strategies on the outcomes, except for its effect on positive

21 affect. That is, engagement-oriented coping strategies were linked to the experience of positive

22 affect right after an examination much more for women than for men. This variable on its own

23 explained $15 \%$ of the gender differences between men and women on the coping-to-positive 
1 affect links. Tamres et al. (2002) also found that the use of engagement-oriented coping could

2 benefit women more in situations where the outcome is associated with greater perceived control

3 and lower perceived threat. In the present study, it is possible that women who experienced the

4 greater increase in positive affect as a result of using engaging strategies also experienced greater

5 control and less threat during their mid-term examination. In sum, our results show that gender

6 differences on the links between engagement-oriented coping and outcomes lead to inconclusive

7 results as to which gender benefit the most from this type of coping strategy. On the other hand,

8 our results clearly show that disengagement-oriented strategies lead to less adaptive outcomes in

9 educational contexts, especially for men. Studying gender differences in the use and

10 effectiveness of these types of strategies with various research designs and outcomes is likely to

11 be a fertile avenue for future research.

\section{4.4. Practical implications}

13 Our findings support the importance of promoting autonomous motivation and

14 engagement-oriented coping strategies in educational and achievement settings. These results

15 can provide a structure for universities to design policies that acknowledge the importance of

16 fostering adaptive responses to stress, especially in examination periods. Our results can be

17 helpful in creating professional development programs that would help educators support

18 autonomous motivation of their students, by focussing on the learning processes rather than the

19 grades, and on providing students with "toolkits" of engagement-oriented coping strategies to

20 use during assessment periods. Although our results were especially striking for male students,

21 we believe that promoting the use of engagement-oriented coping strategies would also be

22 beneficial to female students, who are more likely to perceive assessment and examinations as

23 stressful. 


\subsection{Limitations and future directions}

There are limitations of the current study that might lead to interesting areas for future

3 research. First, most of the measures included in the present research were self-reported.

4 Fortunately, these measures were substantiated by objective measures of achievement, and the

5 mostly consistent findings reported in the cross-validation facilitate the generalization of the

6 findings. An exception to this was the high correlation coefficient found between autonomous

7 and controlled motivations in Study 1. Future research should further investigate the validity of

8 autonomous and controlled motivations with musicians. In addition, the present studies spanned

9 several weeks and thus attrition was to be expected. The attrition rates were consistent with those

10 reported in past research involving similar populations, but attrition can reduce the power of the

11 effects found in the studies. Future research is needed to replicate our findings with larger sample

12 sizes and with research designs spanning a longer period of time to ensure the generalization of

13 the findings. Including more environmental factors, such as measures of autonomy-supportive

14 and controlling environments in future research could provide a broader picture of the

15 determinants of motivation and coping in educational contexts. Future research should also

16 clarify the relationships between engagement and disengagement-oriented coping, and we draw

17 particular attention to the large effect of disengagement coping on examination performance for

18 men, that needs to be further investigated. The examination of the autonomous or controlling

19 assessment contexts was outside the scope of the present research, but future research should

20 address this issue. In addition, using experimental study designs to evaluate the roles of

21 motivation and coping in controlled environments could help further understand the mechanisms

22 underlying gender differences in the coping-to-outcome processes. Finally, the measure of

23 coping used did not examine all the possible coping strategies used in evaluation contexts. Future 
1 research should examine the coping processes with broader and more varied measures of coping

2 strategies.

13 was particularly detrimental to the academic adjustment of male students, who saw their grades

14 dramatically decrease as a result of using such strategies. Since the moderating role of gender has

15 been overlooked in past research linking motivation and coping to academic outcomes, our

16 research opens new areas for future research. 
1 13 estimated between groups.

\section{Footnote}

1. Metric invariance was not met, with four out of five of the fit indices being above the delta thresholds for equivalence. Modification indices indicated that freeing the factor loading of one engagement item ("I've been thinking hard about what steps to take") between men and women resulted in measurement equivalence between groups. With this partial invariance model, we further validated the scalar level of equivalence by constraining the items intercepts to equality and freeing the factor means.

2. Partial scalar invariance with the intercept of the item "Because this will help me make a better choice regarding my career orientation." allowed to be freely estimated, indicated a good model fit of the partial scalar invariance model, $\Delta \chi^{2}(11)=19.67, p=.05$.

3. Partial scalar invariance was met when the intercept of the item "Hostile" that was freely 


\section{References}

Ajzen, I. (2001). Nature and operation of attitudes. Annual Review of Psychology, 52, 27-58. doi:10.1146/annurev.psych.52.1.27

Alivernini, F., \& Lucidi, F. (2011). Relationship between social context, self-efficacy, motivation, academic achievement, and intention to drop out of high school: A longitudinal study. The Journal of Educational Research, 104, 241-252. doi:10.1080/00220671003728062

Amabile, T. M. M. (1979). Effects of external evaluation on artistic creativity. Journal of Personality and Social Psychology, 37, 221-233. doi:10.1080/10400410902861778

Amiot, C. E., Blanchard, C., \& Gaudreau, P. (2008). The self in change: A longitudinal investigation of coping and self-determination processes. Self and Identity. doi:10.1080/15298860701580793

Amiot, C. E., Gaudreau, P., \& Blanchard, C. (2004). Self-determination, coping, and goal attainment in sport. Journal of Sport and Exercise Psychology, 26, 386-411.

Anshel, M. H., Sutarso, T., \& Jubenville, C. (2009). Racial and gender differences on sources of acute stress and coping style among competitive athletes. The Journal of Social Psychology, 149, 159-177. doi:10.3200/SOCP.149.2.159-178

Aspinwall, L. G., \& Taylor, S. E. (1992). Modeling cognitive adaptation: A longitudinal investigation of the impact of individual differences and coping on college adjustment and performance. Journal of Personality and Social Psychology, 63, 989-1003.

Bong, M. (2001). Role of self-efficacy and task-value in predicting college students' course performance and future enrollment intentions. Contemporary Educational Psychology, 26, 553-570. doi:10.1006/ceps.2000.1048

Bonneville-Roussy, A., Vallerand, R. J., \& Bouffard, T. (2013). The roles of autonomy support 
and harmonious and obsessive passions in educational persistence. Learning and Individual Differences, 24, 22-31. doi:10.1016/j.lindif.2012.12.015

Byrne, B. M. (1994). Burnout: Testing for the validity, replication, and invariance of causal structure across elementary, intermediate, and secondary teachers. American Educational Research Journal, 31, 645-673. doi:10.3102/00028312031003645

Byrne, B. M. (2012). Structural equation modeling with Mplus : Basic concepts, applications, and programming (Routledge). New York.

Byrne, B. M., \& van de Vijver, F. J. R. (2010). Testing for measurement and structural equivalence in large-scale cross-cultural studies: Addressing the issue of nonequivalence. International Journal of Testing, 10, 107-132. doi:10.1080/15305051003637306

Carver, C. S. (1997). You want to measure coping but your protocol' too long: Consider the brief cope. International Journal of Behavioral Medicine, 4, 92-100. doi:10.1207/s15327558ijbm0401_6

Carver, C. S., \& Connor-Smith, J. K. (2010). Personality and coping. Annual Review of Psychology, 61, 679-704. doi:10.1146/annurev.psych.093008.100352

Carver, C. S., Scheier, M. F., \& Weintraub, J. K. (1989). Assessing coping strategies: A theoretically based approach. Journal of Personality and Social Psychology, 56, 267-283. doi:10.1037/0022-3514.56.2.267

Chemers, M. M., Hu, L., \& Garcia, B. F. (2001). Academic self-efficacy and first year college student performance and adjustment. Journal of Educational Psychology, 93, 55-64. doi:10.1037/0022-0663.93.1.55

Chen, F. (2007). Sensitivity of goodness of fit indexes to lack of measurement invariance. Structural Equation Modeling, 14, 464-504. 
Connor-Smith, J. K., Compas, B. E., Wadsworth, M. E., Thomsen, A. H., \& Saltzman, H. (2000). Responses to stress in adolescence: Measurement of coping and involuntary stress responses. Journal of Consulting and Clinical Psychology, 68, 976-992. doi:10.1037//0022006X.68.6.976

Connor-Smith, J. K., \& Flachsbart, C. (2007). Relations between personality and coping: A metaanalysis. Journal of Personality and Social Psychology, 93, 1080-1107.

Crocker, P. R. E., \& Graham, T. R. (1995). Coping by competitive athletes with performance stress: Gender differences and relationships with affect. The Sport Psychologist, 9, 325-338.

Deci, E. L., \& Ryan, R. M. (1985). Intrinsic motivation and self-determination in human behavior. New York: Plenum.

Deci, E. L., Vallerand, R. J., Pelletier, L. G., \& Ryan, R. M. (1991). Motivation and education: The self-determination perspective. Educational Psychologist, 26, 325-346. doi:10.1080/00461520.1991.9653137

Doron, J., Stephan, Y., Boich, Julie, \& Le Scanff, C. (2009). Coping with examinations: Exploring relationships between students' coping strategies, implicit theories of ability, and perceived control. British Journal of Educational Psychology, 79, 515-528.

Eicher, V., Staerklé, C., \& Clémence, A. (2014). I want to quit education: A longitudinal study of stress and optimism as predictors of school dropout intention. Journal of Adolescence, 37, 1021-1030. doi:10.1016/j.adolescence.2014.07.007

Evans, P. (2015). Self-determination theory: An approach to motivation in music education. Musicae Scientiae, 19, 65-83. doi:10.1177/1029864914568044

Folkman, S. (1984). Personal control and stress and coping processes: A theoretical analysis. Journal of Personality and Social Psychology, 46, 839-852. doi:10.1037/0022- 
3514.46 .4 .839

Folkman, S., \& Lazarus, R. S. (1985). If it changes it must be a process: Study of emotion and coping during three stages of a college examination. Journal of Personality and Social Psychology, 48, 150-170. doi:10.1037/0022-3514.48.1.150

Folkman, S., \& Moskowitz, J. T. (2004). Coping: Pitfalls and promise. Annual Review of Psychology, 55, 745-774. doi:10.1146/annurev.psych.55.090902.141456

Gaudreau, P., \& Antl, S. (2008). Athletes broad dimensions of dispositional perfectionism: Examining changes in life satisfaction and the mediating role of sport-related motivation and coping. Journal of Sport \& Exercise Psychology, 30, 356-382.

Gaudreau, P., \& Blondin, J. P. (2002). Development of a questionnaire for the assessment of coping strategies employed by athletes in competitive sport settings. Psychology of Sport and Exercise, 3, 1-34. doi:10.1016/S1469-0292(01)00017-6

Gaudreau, P., Carraro, N., \& Miranda, D. (2012). From goal motivation to goal progress: The mediating role of coping in the Self-Concordance Model. Anxiety, Stress \& Coping, 25, 507-528. doi:10.1080/10615806.2011.628015

Gaudreau, P., El Ali, M., \& Marivain, T. (2005). Factor structure of the Coping Inventory for Competitive Sport with a sample of participants at the 2001 New York marathon. Psychology of Sport and Exercise, 6, 271-288. doi:10.1016/j.psychsport.2004.01.002

Gaunt, H. (2008). One-to-one tuition in a conservatoire: The perceptions of instrumental and vocal teachers. Psychology of Music, 36, 215-245. doi:10.1177/0305735607080827

Gillet, N., Vallerand, R. J., Lafrenière, M.-A. K., \& Bureau, J. S. (2012). The mediating role of positive and negative affect in the situational motivation-performance relationship. Motivation and Emotion. doi:10.1007/s11031-012-9314-5 
Grolnick, W. S., \& Ryan, R. M. (1987). Autonomy in children's learning: An experimental and individual difference investigation. Journal of Personality and Social Psychology, 52, 890898.

Grouzet, F. M. E., Otis, N., \& Pelletier, L. G. (2006). Longitudinal cross-gender factorial invariance of the Academic Motivation Scale. Structural Equation Modeling: A Multidisciplinary Journal. doi:10.1207/s15328007sem1301_4

Hammermeister, J., \& Burton, D. (2004). Gender differences in coping with endurance sport stress: Are men from mars and women from venus? Journal of Sport Behavior, 27, 148164.

Kaiseler, M., Polman, R. C. J., \& Nicholls, A. R. (2012). Gender differences in appraisal and coping: An examination of the situational and dispositional hypothesis. International Journal of Sport Psychology, 43, 1-14.

Kaiseler, M., Polman, R. C. J., \& Nicholls, A. R. (2013). Gender differences in stress, appraisal, and coping during golf putting. International Journal of Sport and Exercise Psychology, 11, 258-272. doi:10.1080/1612197X.2013.749004

Kaiseler, M., Polman, R., \& Nicholls, A. (2009). Mental toughness, stress, stress appraisal, coping and coping effectiveness in sport. Personality and Individual Differences, 47, 728733. doi:10.1016/j.paid.2009.06.012

Knee, C. R., \& Zuckerman, M. (1998). A nondefensive personality: Autonomy and control as moderators of defensive coping and self-handicapping. Journal of Research in Personality, 32, 115-130. doi:10.1006/jrpe.1997.2207

Lavigne, G. L., Vallerand, R. J., \& Miquelon, P. (2007). A motivational model of persistence in science and education: A self-determination theory approach. European Journal of 
Psychology of Education, 22, 351-69.

Lawrence, J., Ashford, K., \& Dent, P. (2006). Gender differences in coping strategies of undergraduate students and their impact on self-esteem and attainment. Active Learning in Higher Education, 7, 273-281. doi:10.1177/1469787406069058

Lazarides, R., \& Watt, H. M. G. (2015). Girls' and boys' perceived mathematics teacher beliefs, classroom learning environments and mathematical career intentions. Contemporary Educational Psychology, 41, 51-61. doi:10.1016/j.cedpsych.2014.11.005

Lazarus, R. S., \& Folkman, S. (1984). Stress, appraisal, and coping. New York: Springer.

Lazarus, R. S., \& Folkman, S. (1991). The concept of coping. In Stress and coping: An anthology (3rd ed.). (pp. 189-206). New York, NY, US: Columbia University Press.

Lengua, L. J., \& Stormshak, E. A. (2000). Gender, gender roles, and personality: Gender differences in the prediction of coping. Sex Roles, 43, 787-820. doi:10.1023/A:1011096604861

Low, K. S. D., Yoon, M., Roberts, B. W., \& Rounds, J. (2005). The stability of vocational interests from early adolescence to middle sdulthood: A quantitative review of Longitudinal studies. Psychological Bulletin, 131, 713-737. doi:10.1037/0033-2909.131.5.713

Marsh, H. W., Hau, K.-T., \& Wen, Z. (2004). In search of golden rules: Comment on hypothesistesting approaches to setting cutoff values for fit indexes and dangers in overgeneralizing Hu and Bentler's (1999) findings. Structural Equation Modeling: A Multidisciplinary Journal, 11, 320-341. doi:10.1207/s15328007sem1103_2

Marsh, H. W., Muthén, B., Asparouhov, T., Lüdtke, O., Robitzsch, A., Morin, A. J. S., \& Trautwein, U. (2009). Exploratory structural equation modeling, integrating CFA and EFA: Application to students' evaluations of university teaching. Structural Equation Modeling: 
A Multidisciplinary Journal, 16, 439-476. doi:10.1080/10705510903008220

Marsh, H. W., Nagengast, B., \& Morin, A. J. S. (2013). Measurement invariance of big-five factors over the life span: ESEM tests of gender, age, plasticity, maturity, and la dolce vita effects. Developmental Psychology, 49, 1194-218. doi:10.1037/a0026913

Matud, M. P. (2004). Gender differences in stress and coping styles. Personality and Individual Differences, 37, 1401-1415. doi:10.1016/j.paid.2004.01.010

McPherson, G. E., \& Gabrielsson, A. (2002). From sound to sign. In R. Parncutt \& G. E. McPherson (Eds.), The Science and Psychology of Music Performance: Creative Strategies for Teaching and Learning (pp. 99-116). Oxford: Oxford University Press.

Moneta, G. B., \& Spada, M. M. (2009). Coping as a mediator of the relationships between trait intrinsic and extrinsic motivation and approaches to studying during academic exam preparation. Personality and Individual Differences, 46, 664-669. doi:10.1016/j.paid.2009.01.012

Moneta, G. B., Spada, M. M., \& Rost, F. M. (2007). Approaches to studying when preparing for final exams as a function of coping strategies. Personality and Individual Differences, 43, 191-202. doi:10.1016/j.paid.2006.12.002

Muthén, L. K., \& Muthén, B. O. (2010). Mplus Version 7.3. Los Angeles: Muthén \& Muthén.

Nicholls, A. R., \& Polman, R. C. J. (2007). Coping in sport: A systematic review. Journal of Sports Sciences, 25, 11-31.

Nicholls, A. R., Polman, R. C. J., \& Levy, A. R. (2012). A path analysis of stress appraisals, emotions, coping, and performance satisfaction among athletes. Psychology of Sport and Exercise, 13, 263-270. doi:10.1016/j.psychsport.2011.12.003

Nicholls, A. R., Polman, R., Levy, A. R., Taylor, J., \& Cobley, S. (2007). Stressors, coping, and 
coping effectiveness: Gender, type of sport, and skill differences. Journal of Sports Sciences, 25, 1521-1530.

Ntoumanis, N., Biddle, S. J. H., \& Haddock, G. (1999). The mediating role of coping strategies on the relationship between achievement motivation and affect in sport. Anxiety, Stress \& Coping, 12, 299-327. doi:10.1080/10615809908250480

Ntoumanis, N., Edmunds, J., \& Duda, J. L. (2009). Understanding the coping process from a self-determination theory perspective. British Journal of Health Psychology, 14, 249-260. doi:10.1348/135910708X349352

Otis, N., Grouzet, F. M. E., \& Pelletier, L. G. (2005). Latent motivational change in an academic setting: A 3-year longitudinal study. Journal of Educational Psychology, 97, 170-183. doi:10.1037/0022-0663.97.2.170

Ptacek, J. T., Smith, R. E., \& Dodge, K. L. (1994). Gender differences in coping with stress: When stressor and appraisals do not differ. Personality and Social Psychology Bulletin. doi:10.1177/0146167294204009

Putwain, D., \& Remedios, R. (2014). The scare tactic: Do fear appeals predict motivation and exam scores? School Psychology Quarterly, 29, 503-516. doi:10.1037/spq0000048

Ratelle, C. F., Guay, F., Vallerand, R. J., Larose, S., \& Senécal, C. (2007). Autonomous, controlled, and amotivated types of academic motivation: A person-oriented analysis. Journal of Educational Psychology, 99, 734-746. doi:10.1037/0022-0663.99.4.734

Richardson, M., Abraham, C., \& Bond, R. (2012). Psychological correlates of university students' academic performance: A systematic review and meta-analysis. Psychological Bulletin, 138, 353-387. doi:10.1037/a0026838

Rogowska, A., \& Kusnierz, C. (2012). Coping of judo competitors in the context of gender, age, 
years of practice and skill level. Journal of Applied Sport Psychology, 24, 445-464. doi:10.1080/10413200.2012.694392

Rovira, T., Fernandez-Castro, J., \& Edo, S. (2005). Antecedents and consequences of coping in the anticipatory stage of an exam: A longitudinal study emphasizing the role of affect. Anxiety, Stress \& Coping. doi:10.1080/10615800500134654

Ryan, R. M., \& Connell, J. P. (1989). Perceived locus of causality and internalization: Examining reasons for acting in two domains. Journal of Personality and Social Psychology, 57, 749761. doi:10.1037/0022-3514.57.5.749

Ryan, R. M., \& Deci, E. L. (2000a). Intrinsic and extrinsic motivations: Classic definitions and new directions. Contemporary Educational Psychology. Special Issue: Motivation and the Educational Process, 25, 54-67.

Ryan, R. M., \& Deci, E. L. (2000b). Self-determination theory and the facilitation of intrinsic motivation, social development, and well-being. American Psychologist, 55, 68-78.

Ryan, R. M., \& Weinstein, N. (2009). Undermining quality teaching and learning: A selfdetermination theory perspective on high-stakes testing. Theory and Research in Education, 7, 224-233. doi:10.1177/1477878509104327

Saklofske, D. H., Austin, E. J., Mastoras, S. M., Beaton, L., \& Osborne, S. E. (2012). Relationships of personality, affect, emotional intelligence and coping with student stress and academic success: Different patterns of association for stress and success. Learning and Individual Differences, 22, 251-257. doi:10.1016/j.lindif.2011.02.010

Schellenberg, B. J. I., \& Bailis, D. S. (2016). The two roads of passionate goal pursuit: Links with appraisal, coping, and academic achievement. Anxiety, Stress, \& Coping, 29, 287-304. doi:10.1080/10615806.2015.1036047 
Schellenberg, B. J. I., Gaudreau, P., \& Crocker, P. R. E. (2013). Passion and coping:

Relationships with changes in burnout and goal attainment in collegiate volleyball players. Journal of Sport \& Exercise Psychology, 35, 270-80.

Schoon, I. (2001). Teenage job aspirations and career attainment in adulthood: A 17-year followup study of teenagers who aspired to become scientists, health professionals, or engineers. International Journal of Behavioral Development, 25, 124-132. doi:10.1080/01650250042000186

Skinner, E. A., Edge, K., Altman, J., \& Sherwood, H. (2003). Searching for the structure of coping: A review and critique of category systems for classifying ways of coping. Psychological Bulletin, 129, 216-269.

Skinner, E. A., Pitzer, J., \& Steele, J. (2013). Coping as part of motivational resilience in school: A multidimensional measure of families, allocations, and profiles of academic coping. Educational and Psychological Measurement, 73, 803-835. doi: $10.1177 / 0013164413485241$

Smith, J. P., \& Naylor, R. A. (2001). Dropping out of university: A statistical analysis of the probability of withdrawal for UK university students. Journal of the Royal Statistical Society. Series A (Statistics in Society), 164, 389-405. doi:10.1111/1467-985X.00209

Steptoe, A. (1989). Stress, Coping and Stage Fright in Professional Musicians. Psychology of Music, 17, 3-11. doi:10.1177/0305735689171001

Steptoe, A. (1989). Stress, coping and stage fright in professional musicians. Psychology of Music, 17, 3-11. doi:10.1177/0305735689171001

Syrjala, M., Saarela, H., \& Lehtonen, K. (2005). The relationship between master music teachers and master students: Counseling concerns. Gifted Education International, 19, 275-278. 
doi:10.1177/026142940501900311

Tamres, L. K., Janicki, D., \& Helgeson, V. S. (2002). Sex differences in coping behavior: A meta-analytic review and an examination of relative coping. Personality and Social Psychology Review. doi:10.1207/S15327957PSPR0601_1

Taylor, G., Jungert, T., Mageau, G. A., Schattke, K., Dedic, H., Rosenfield, S., \& Koestner, R. (2014). A self-determination theory approach to predicting school achievement over time: The unique role of intrinsic motivation. Contemporary Educational Psychology, 39, 342358. doi:10.1016/j.cedpsych.2014.08.002

Thompson, A., \& Gaudreau, P. (2008). From optimism and pessimism to coping: The mediating role of academic motivation. International Journal of Stress Management. doi:10.1037/a0012941

Titus, M. A. (2004). An examination of the influence of institutional context on student persistence at 4-year colleges and universities: A multilevel approach. Research in Higher Education, 45, 673-699. doi:10.1023/B:RIHE.0000044227.17161.fa

Vallerand, R. J., Fortier, M. S., \& Guay, F. (1997). Self-determination and persistence in a reallife setting: Toward a motivational model of high school dropout. Journal of Personality and Social Psychology, 72, 1161-1176. doi:10.1037/0022-3514.72.5.1161

Vallerand, R. J., Pelletier, L. G., Blais, M. R., Brière, N. M., Senécal, C. B., \& Vallières, É. F. (1992). The Academic Motivation Scale: A measure of intrinsic, extrinsic, and amotivation in education. Educational and Psychological Measurement, 52, 1003-1017.

Vallerand, R. J., Pelletier, L. G., Blais, M. R., Briere, N. M., Senecal, C., \& Vallieres, E. F. (1993). On the assessment of intrinsic, extrinsic, and amotivation in education: Evidence on the concurrent and construct validity of the Academic Motivation Scale. Educational and 
Psychological Measurement, 53, 159-172. doi:10.1177/0013164493053001018

Vallerand, R. J., \& Senécal, C. B. (1992). Une analyse motivationnelle de l'abandon des Études. / A motivational analysis of dropping out of school. Apprentissage et Socialisation, 15, 4962.

van Yperen, N. W. (2009). Why some make it and others do not : Identifying psychological factors that predict career success in professional adult soccer. Sport Psychologist, 23, 317329.

Vansteenkiste, M., Simons, J., Lens, W., Sheldon, K. M., \& Deci, E. L. (2004). Motivating learning, performance, and persistence: The synergistic effects of intrinsic goal contents and autonomy-supportive contexts. Journal of Personality and Social Psychology, 87, 246-260. doi:10.1037/0022-3514.87.2.246

Verner-Filion, J., Vallerand, R. J., Donahue, E. G., Moreau, E., Martin, A., \& Mageau, G. A. (2014). Passion, coping, and anxiety in sport: The interplay between key motivational and self-regulatory processes. International Journal of Sport Psychology, 45, 516-537.

von der Embse, N. P., Schultz, B. K., \& Draughn, J. D. (2015). Readying students to test: The influence of fear and efficacy appeals on anxiety and test performance. School Psychology International, 36, 620-637. doi:10.1177/0143034315609094

Voyer, D., \& Voyer, S. D. (2014). Gender differences in scholastic achievement: A meta-analysis. Psychological Bulletin, 140, 1174-1204. doi:10.1037/a0036620

Wang, M.-T. (2012). Educational and career interests in math: A longitudinal examination of the links between classroom environment, motivational beliefs, and interests. Developmental Psychology, 48, 1643-1657. doi:10.1037/a0027247

Watson, D., Clark, L. a, \& Tellegen, A. (1988). Development and validation of brief measures of 
positive and negative affect: The PANAS scales. Journal of Personality and Social Psychology, 54, 1063-1070. doi:10.1037/0022-3514.54.6.1063

Watson, D., \& Clark, L. A. (1999). The PANAS-X: Manual for the positive and negative affect schedule - expanded form. The University of Iowa.

Zeidner, M. (1995). Coping with examination stress: Resources, strategies, outcomes. Anxiety, Stress \& Coping, 8, 279-298. doi:10.1080/10615809508249379

Zimmerman, B. J., \& Martinez-Pons, M. (1990). Student differences in self-regulated learning: Relating grade, sex, and giftedness to self-efficacy and strategy use. Journal of Educational Psychology, 82, 51-59. doi:10.1037/0022-0663.82.1.51

Zuckerman, M., Kieffer, S. C., \& Knee, C. R. (1998). Consequences of self-handicapping: effects on coping, academic performance, and adjustment. Journal of Personality and Social Psychology, 74, 1619-1628. doi:10.1037/0022-3514.74.6.1619 